\title{
Knowledge and Beliefs about the Inclusion of Health Warnings on Waterpipe Tobacco Packaging in Jordan
}

\author{
Sukaina Alzyoud ${ }^{1,2}$, Hala Boukerdenna ${ }^{2}$, Ahmad Abbadi $^{2} \&$ Linda S. Weglicki $^{3}$ \\ ${ }^{1}$ Department of Community and Mental Health, Faculty of Nursing, Hashemite University, Zarqa, Jordan \\ ${ }^{2}$ World Health Organization Country Office of Jordan, Amman, Jordan \\ ${ }^{3}$ Collage of Nursing, Medical University of South Carolina, Charleston, USA \\ Correspondence: Sukaina Alzyoud, Faculty of Nursing, Hashemite University, Zarqa, Jordan. Tel: \\ 962-799-986-265
}

Received: January 31, 2021 Accepted: March 9, 2021 Online Published: May 17, 2021

doi:10.5539/gjhs.v13n6p134 URL: https://doi.org/10.5539/gjhs.v13n6p134

\begin{abstract}
Background: Article 11 of WHO-FCTC strategies emphasize the need for countries to include health warnings on packages of tobacco products. This study aims to assess Jordanian people, aged 13 years and above knowledge and beliefs about the inclusion of health warning labels on waterpipe tobacco packages.

Methods: A descriptive cross-sectional approach was conducted among youth and adults aged 13 years and above. The sample was recruited from public schools, universities, and a governmental public service agency. Data collection was done through an electronic survey using Tablets.
\end{abstract}

Results: A total of 1067 participated in the study, with ages ranging between 13- 63 years old with a mean (20.9, $\mathrm{SD}= \pm 6.1)$. Study participants mainly consisted of students making $(86.7 \%)$ of the total sample. These students were in secondary education school (19.3\%) or attending university $(67.4 \%)$. Findings indicated that participants tobacco smoking status were non-smokers, single type smoker, dual smoker, and triple smokers $(67.8 \%, 21.6 \%$, $6.8 \%$, and $3.7 \%$ respectively). In comparison the prevalence of smoking single tobacco type, dual smoking, and triple smokers tobacco products was statistically higher among males than females $(11.1 \%-10.6 \%, 5.1 \%-1.8 \%$, and $3.1 \%-0.7 \%$ respectively). Eighty-seven percent knew that waterpipe smoking is harmful and would support the inclusion of health warnings on the tobacco packet. Thirty percent indicated that the inclusion of health warnings will greatly improve their knowledge of the harmful effects of tobacco smoking.

Conclusion: The current study shows that participants believe including health warnings on waterpipe tobacco package would help smokers to think about quitting.

Keywords: waterpipe; beliefs; health warning, smoking, knowledge, tobacco

\section{Introduction}

Worldwide waterpipe tobacco smoking prevalence increased dramatically over the past decade (WHO World Health Organization, 2003). Waterpipe smoking involves flavored tobacco where a burning charcoal is put on top of the flavored tobacco and the smoke produced is drawn through the water and is inhaled by the user or users through a hose (C. O. Cobb, Khader, Nasim, \& Eissenberg, 2012). Reports from the last two decades showed that waterpipe smoking continues to increase in high numbers in both developing (Abu-Rmeileh et al., 2018; Akl et al., 2011; W. Maziak et al., 2004; Tucktuck, Ghandour, \& Abu-Rmeileh, 2017) and developed countries (Aljarrah, Ababneh, \& Al-Delaimy, 2009; C. Cobb, Ward, Maziak, Shihadeh, \& Eissenberg, 2010) . Early reports indicated that waterpipe smoking prevalence was higher among males (Smith-Simone, Maziak, Ward, \& Eissenberg, 2008; Sterling \& Mermelstein, 2011). However, in recent years a growing number of studies have shown that female waterpipe smokers are also high and sometimes equal in numbers to male smokers (Alzyoud, Weglicki, Kheirallah, Haddad, \& Alhawamdeh, 2013; Wasim Maziak, 2011; Tamim et al., 2007; World Health Organization Advisory note, 2015).

Waterpipe smoking has become a global health problem spreading from Middle Eastern to Western societies (Wasim Maziak, 2011; Wasim Maziak et al., 2015). Based upon 2005-2008 reports, frequency of use (from past 30 days to regular and occasional use) varied by country and age of waterpipe smoker (youth or young adult) with highest use among Lebanese youth (37\%), Iranian university aged students (16.3\%), and Egyptian youth (10.4\%), 
respectively. A recent systematic review analyzing 129 waterpipe smoking studies among young adults, showed that university students had the highest prevalence estimates of waterpipe smoking worldwide (Jawad et al., 2018). This continuing and disturbing increase in tobacco use among the world youth and young adult population prompted the World Health Organization (WHO) to declare waterpipe smoking as a growing public health concern in 2015 (Waziry, Jawad, Ballout, Al Akel, \& Akl, 2016; World Health Organization Advisory note, 2015). Several researchers demonstrated that waterpipe smoking, exposes the person to volatile aldehydes, polycyclic aromatic hydrocarbons and carbon monoxide, which can all lead to the development of respiratory diseases and cancer (Shihadeh \& Saleh, 2005; Shihadeh et al., 2015). The effects are exacerbated by the addiction caused by nicotine leading to nicotine dependence (Aboaziza \& Eissenberg, 2015; Bahelah et al., 2017; Chaouachi, 2006). Furthermore, studies have linked waterpipe smoking to depressive symptoms among youth (Abbadi et al., 2020; Alzyoud \& Massoud, 2020).

In the last few years, tobacco use in Jordan has been reported to be among the highest in the world (WHO World Health Organization, 2018). Waterpipe smoking in Jordan is high among both sexes (Abu-Rmeileh et al., 2018; Alzyoud et al., 2013) with a prevalence of $17.9 \%$ (24.6\% for males, $11.2 \%$ for females) (Center for Disease Control and Prevention, 2017). Another study reported the total prevalence for waterpipe smoking to be $41 \%$ among Jordanian youth and young adults when gender is combined (Abu-Rmeileh et al., 2018). These alarming prevalence's call for serious actions for tobacco prevention and control efforts in order to reduce the well-established harmful effects of waterpipe smoking (Haddad et al., 2016; Waziry et al., 2016; World Health Organization Advisory note, 2015). Such actions could be in the shape of educating the public about the harms of tobacco use. The World Health Organization Framework Convention on Tobacco Control (WHO-FCTC) covers a wide range of tobacco control strategies that obliges ratifying parties to comply with its provisions. Among these WHO-FCTC strategies, Article 11, specifically addresses packaging and labelling of tobacco products to include health warnings that should cover at least $50 \%$ the front and back of the package.

Jordan, in 2004, was among the first countries to ratify the FCTC; however, there was slow and minimal progress made in relation to the inclusion of health warning on tobacco products packaging. Currently, four pictorial health warnings are included on cigarette packages (Bader, Shihab, Al-Rimawi, \& Hawari, 2017), while only one pictorial health warning is inserted on waterpipe tobacco packages (Jordan Standards and Metrology Organization, 2014). In their cross-sectional study of 1250 youth and young adults, 17-26 years of age, Bader and colleagues reported that one-third of cigarette smoking participants noted pictorial health warning labels and that these labels triggered consideration of quitting. Moreover, when they were shown the health warning labels on cards similar in size to the one added to the cigarette packet, both cigarette smokers and non-smokers sustained the ability to motivate quitting and staying smoke-free. A previous study (Hawari et al., 2011) tested Jordanian 17 to 26 year old's perceptions towards introducing health warning labels on cigarette packages. Their results showed that health warning labels significantly motivated around $30 \%$ of smokers to consider quitting. Both studies were conducted among those aged 17 to 26 years, and excluded adolescents and those older than 26 years of age, where waterpipe smoking prevalence is known to be high in Jordan.

The use and impact of health warning labels on the cigarette packet on smokers quitting has important implications for examining whether the effects of health warning labels on waterpipe packaging would have the same use and impact. Over the years, researchers measured a wide range of variables impacting the implementation of health warnings on tobacco packages (Francis, Hall, Noar, Ribisl, \& Brewer, 2017; Girisken, Eser Telci, Arikan, \& Kefallonitis, 2017; Ratneswaran et al., 2014). A systematic review by Francis et al., (2017) demonstrated that when participants perceive health warnings as effective in communicating the harmful effects of smoking, the warning labels could be more effective in changing attitudes, intentions, and behaviors toward smoking.

Furthermore, health warnings that includes consequences of smoking such as diseases were found to be effective in changing people beliefs about smoking (Ratneswaran et al., 2014). In a recent collaboration between the WHO-Country Office and Jordanian Ministry of Health efforts to propose a policy for the expansion of health warning labels on waterpipe tobacco packages a study was conducted aiming to assess Jordanians, aged 13 years and above about their knowledge and beliefs about the inclusion of health warning labels on waterpipe tobacco (also called "Moa'ssal") packages regardless of their smoking status.

\section{Methodology}

\subsection{Study Design and Sample}

A descriptive cross-sectional study design was conducted to assess Jordanian's knowledge and beliefs about the inclusion of health warning labels on waterpipe tobacco "Moa'ssal" packages. 
The study was conducted among the youth and adults aged 13 years and above of the Jordanian population: adolescents 13-18 years, young adults 19-35 years, and adults above 35 years. Our sample was recruited from public and private schools in Amman Governorate, public and private universities, and civil service departments. Eligible participants who were able to read Arabic, use smart device "Tablet", meet study age group were recruited from schools in Amman Governorate, Civil Services Departments CSDs in Amman Governorate, and Five universities [3 public, 2 privates] that cover all three regions (North, Center, South) of the country.

Prior to data collection, a list of all Amman governorate schools was obtained from the Ministry of Education (MOE). The next step was to make two lists one for boys' and one for girls' schools. After that, the researchers randomly selected boys' school and girls' schools for data collection. The inclusion criteria were being a school that compasses the age group 13-18 and being in Amman. Schools were limited to the Amman governorate because it comprises more than $40 \%$ of the Jordanian population (Department of Statistics, 2019). According to the MOE number of schools was almost equal for sex.

The CSD receive an average of 200-300 individuals on a daily basis. These departments were selected to recruit participants in the adult age group. The research team selected the CSD to access the age category 35 years or in one sitting. The CSD is visited daily by individuals for various essential civil services such as issuing and/or renew National ID cards, passports, birth and marriage certificates. This department provide services for nationals and non-nationals. CSD clients change daily and represent different social, educational, and economic backgrounds. Power analysis was conducted to determine the required sample size. Setting the power at 0.8 and alpha at 0.05 , the total sample size was estimated to be a total of 1500 participants. However, due to logistic reasons such as weak internet connection, device deficiency, conflict with official holidays and school breaks the final sample recruited was 1067 participant.

\subsection{Measures and Data Collection}

The current study was approved for human protection concerns by the Institutional Review Board (IRB) committee of Hashemite University, and approved by the Ministry of Education and Ministry of Health in Jordan. Participants were asked to complete an electronic survey using "Google Forms" to assess knowledge and beliefs about the inclusion of health warning labels on waterpipe tobacco packages. Participants were approached by the research team and asked if they would like to participate in the study, then a brief description of study purpose was provided if they agree. The instrument used for this study was developed by the research team to address the youth and adults knowledge and beliefs toward health warnings on "Moa'ssal" packages. The survey asked participants about their age, sex, job, educational level, smoking behavior (type of tobacco they use and frequency of waterpipe smoking daily, weekly, and monthly which refers to times smoking tobacco during the last 30 days as defined by the Center for Disease Control) and opinions on the harms of smoking. For the purpose of this study tobacco smoking status was measured for current smoking and divided the participants as non-smoker (never smoked any type of tobacco products), single type smoking (smoking one product only cigarette, waterpipe, or e-cigarette even if once during the last month), dual type smoking (smoking any two of the three previous mentioned products even if once during the last month), and triple smoking (smoking all three products even if once during the last month). The measure also asks participants if the inclusion of health warning labels on waterpipe tobacco package would improve their knowledge of the health effects of tobacco smoking. Participants were asked about their beliefs toward adding health warning labels on tobacco package. They were also asked to report how the inclusion of health warning labels would affect a person's beliefs toward tobacco. This was measured with the inclusion of five sentences were the participants would indicate their beliefs about them by three-point Likert-scale type choices [less likely, make no difference, more likely]. These statements were drawn from the literature as the most frequently reported reactions of exposure to health warnings: (a.) make you think of the health risk of waterpipe smoking, (b.) It will convey the potential unhealthy and negative effect of waterpipe smoking effectively, (c.) It will arouse fear of waterpipe smoking, (d.) it will encourage waterpipe smokers to quit, (e.) It will encourage none smokers, in general, to think not to initiate smoking.

To increase the efficiency of data collection, trained research assistants (males \& females) were present in all study locations during recruitment and consenting. Participants were asked if they would like to volunteer to participate in a research study on tobacco product labeling and pictorial health warnings. For school aged students, the lead researcher approached school officials and teachers who then distributed information letters and consent forms, which were sent to students' parents with the students, who provided written consent for their child's study participation. Following consenting, eligible student participants completed the survey in the classroom using Tablets. Students took, on average, 30 minutes time to complete the electronic survey.

For participants aged 18 years or older the research team recruited them by approaching them personally at the 
above-mentioned settings from universities and governmental service departments. The research team then obtain interested participants written consent form to participate in the study. All participants were assured that participation is anonymous, and they will not be identified. This was assured through not asking any identifying information from participants. All consent forms are safely locked in a file cabinet in the lead researcher research office.

Survey data was only accessible by the lead researcher and no one else had access to it. All collected data was stored on a secured server at the lead researcher institution with high cyber security measures.

\subsection{Statistical Analysis}

The Statistical Package for the Social Science (SPSS) version 23 was used to analyze the data. Analysis of frequency (chi-square test) was used to determine the relationship between participants age, sex, educational level, occupation and tobacco use status. Backward elimination multiple logistic regression was performed to assess the relationship between smoking status and participants' demographics, knowledge and beliefs about health warnings. $P$-values $<0.05$ were considered significant. The collinearity was checked for in the logistic regression model.

\section{Results}

The final sample consisted of 1067 participants (see Table 1 for sample characteristics). Participants ages ranged between $13-63$ years old with a mean $(20.9, \mathrm{SD}= \pm 6.01)$. More than half of the sample was female participants $(54.5 \%)$. Participants mainly consisted of students $(86.7 \%)$ who were in secondary education school $(19.3 \%)$ or attending university (67.4\%).

Table 1. Sample Characteristics $n=1067$

\begin{tabular}{|c|c|c|}
\hline Variable & $\mathbf{N}$ & $\%$ \\
\hline \multicolumn{3}{|l|}{ Age } \\
\hline $13-18$ years & 235 & 22 \\
\hline $19-35$ years & 774 & 72.5 \\
\hline$>35$ years & 58 & 5.4 \\
\hline \multicolumn{3}{|l|}{ Sex } \\
\hline Female & 581 & 54.5 \\
\hline Male & 486 & 45.5 \\
\hline \multicolumn{3}{|l|}{ Education Level } \\
\hline 11-12 Grade & 295 & 27.6 \\
\hline 8-10 Grade & 134 & 12.6 \\
\hline BA or higher Ed Degree & 605 & 56.7 \\
\hline Community college & 33 & 3.1 \\
\hline \multicolumn{3}{|l|}{ Occupation } \\
\hline white-collar job & 93 & 8.7 \\
\hline Home maker & 16 & 1.5 \\
\hline Labor worker & 4 & .4 \\
\hline Private business & 20 & 1.9 \\
\hline Student & 925 & 86.7 \\
\hline Unemployed & 9 & .8 \\
\hline \multicolumn{3}{|l|}{ Tobacco smoking status } \\
\hline Non Smokers & 723 & 67.8 \\
\hline Single type smoker & 231 & 21.6 \\
\hline Dual Smoker & 73 & 6.8 \\
\hline Triple type smoker & 40 & 3.7 \\
\hline
\end{tabular}




\section{WP Smoking Frequency}

Do not smoke WP

Monthly WP smoker (past 30 days)

Weekly WP smoker (past 7 days)

Daily WP smoker

$\begin{array}{rr}720 & 67.5 \\ 214 & 20.1 \\ 92 & 8.6 \\ 41 & 3.8\end{array}$

Participants were asked if they used any of the following tobacco products: cigarette, waterpipe, and/or electronic cigarette. The results showed (Table 1) that tobacco smoking status (as defined in section 2.1. Assessment method) were non smokers, single type smoker, dual smoker, and triple smokers $(67.8 \%, 21.6 \%, 6.8 \%$, and $3.7 \%$ respectively). Monthly waterpipe smoking (smoking waterpipe tobacco during the past 30 days) was the highest frequency $(20.1 \%)$ followed by weekly waterpipe smoking. The chi-squared test was used to test the difference of smoking status and participants sex, education level, and occupation. A significant difference was found between the number of males and females who smoked tobacco products (Table 2). The prevalence of smoking single tobacco type, dual smoking, and triple smokers tobacco products was statistically higher among males than females $(11.1 \%, 5.1 \%$, and $3.1 \%$ respectively), $(\mathrm{p}<0.05)$.

Table 2. Association between sample sex and smoking status

\begin{tabular}{|c|c|c|c|c|c|c|c|}
\hline & & & $\begin{array}{l}\text { None } \\
\text { smoker }\end{array}$ & $\begin{array}{l}\text { Single type } \\
\text { smoker* }\end{array}$ & $\begin{array}{l}\text { Dual } \\
\text { smoker** }\end{array}$ & $\begin{array}{l}\text { Triple } \\
\text { smoker*** }\end{array}$ & P-Value* \\
\hline \multirow{4}{*}{ Sex } & \multirow{2}{*}{ Female } & $\#$ & 442 & 113 & 19 & 7 & \multirow{4}{*}{$<0.05$} \\
\hline & & $\%$ & $41.4 \%$ & $10.6 \%$ & $1.8 \%$ & $0.7 \%$ & \\
\hline & \multirow{2}{*}{ Male } & $\#$ & 281 & 118 & 54 & 33 & \\
\hline & & $\%$ & $26.3 \%$ & $11.1 \%$ & $5.1 \%$ & $3.1 \%$ & \\
\hline
\end{tabular}

$* \mathrm{p}<.05, * *$ Smoking one of the folloing Cigarette, or waterpipe, or e-cigarette, $* * *$ Smoking any two of the three previous mentioned products, $* * * *$ Smoking all three products.

Table 3 present results for knowledge and beliefs toward health warnings. The majority (87\%) knew that waterpipe smoking is harmful and would support the inclusion of health warnings on Moa'ssal packet. When asked if they are aware of any health warnings on the Moa'ssal packet (40.9\%) identified that there are no health warning on the packet. Thirty percent indicated that the inclusion of health warnings will greatly improve their knowledge of harmful effects of tobacco smoking (see Table 3).

Table 3. Participants Knowledge and beliefs toward health warnings

\begin{tabular}{llc}
\hline & $\mathrm{N}$ & $\%$ \\
\hline Would you support adding health warnings on Mo'assal packs similar to cigarette packages & 139 & 13 \\
No & 928 & 87 \\
Yes & 423 & 39.6 \\
\hline Would you say that the inclusion of health warnings and health information on Mo'assal packs will improved your \\
knowledge of the health effects of tobacco consumption & 30.9 \\
A little & 330 & 9.9 \\
A lot & 106 & 19.5 \\
Don't know & 208 & 45.5 \\
makes no difference & 486 \\
\hline Are you aware of any health warnings on Mo'assal packs? & \\
Front of Mo'assal pack & & 4.5 \\
\hline
\end{tabular}




$\begin{array}{lll}\text { Side of Mo'assal pack } & 76 & 7.1 \\ \text { Back of Mo'assal pack } & 69 & 6.5 \\ \text { There are no warning messages } & 436 & 40.9\end{array}$

What do you think the effect of buying a Mo'ssal packet that include health warning would be on the individual

Make you think of the health risk of waterpipe smoking

Less likely

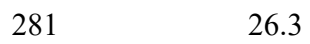

Makes no difference

406

More likely

380

35.6

It will convey potential unhealthy and negative effect of waterpipe smoking effectively

Less likely 335

Makes no difference

More likely

348

32.6

It will arouse fear of waterpipe smoking

Less likely

$301 \quad 28.2$

Makes no difference

More likely

It will encourage waterpipe smokers to quit

Less likely

$345 \quad 32.3$

Makes no difference

More likely

It will encourage none smokers in general to think not to initiate smoking

Less likely

Makes no difference

More likely

392

How important is it that Jordan has health warnings on packs of Mo'assal.

Important

$346 \quad 32.4$

No difference

Unimportant

Very Important

Do you think printing pictorial health warnings about harmful effects on Cigarettes and or waterpipe packs will be/is an effective way to reduce its smoking among young people

$\begin{array}{lll}\text { Helps to prevent smoking } & 147 & 13.8 \\ \text { Helps to smoke } & 23 & 2.2 \\ \text { Helps to stop } & 500 & 46.9 \\ \text { No effect } & 397 & 37.2\end{array}$

More than one third $(35.5 \%)$ of participants believe it is very important to include health warning labels on Moa'ssal packet, with $(46.9 \%)$ believing that health warning labels would be effective in making smokers to reduce smoking. Participants also believed that adding health warning will likely affect a person's thinking about the health risks of waterpipe smoking (35.6\%), to encourage none smokers not to initiate smoking (36.7\%) and arouse fear of waterpipe smoking $(45.1 \%)$. When asked if they believe that it could encourage smokers to quit, only $(27.6 \%)$ said that it would. 
The logistic model was performed to examine the relationship between the outcome variables smoking status with participants' age, sex, knowledge of health warnings, and beliefs about health warnings (see Table 4).

Males were about two times more likely to be smokers compared to females (Odd Ratio [OR], 95\% C.I.: 2.23, 1.69 - 2.95). Participants who identified that there are no health warning on Mo'assal were significantly more likely to be smokers than who did not (OR, $0.60,95 \%$ C.I.: $0.44-0.81$ ). When asked if they think adding health warning would make them think of the harmful effects of tobacco, participants who answered "more likely" were significantly more likely to be none-smokers (OR, 0.49, 95\% C.I.: 0.34-0.71). Believing that it is "very important" to add health warning on Mo'assal packets was more likely among none-smokers (OR, 0.52, 95\% C.I.: 0.36 $0.75)$.

Table 4. Association of smoking status and knowledge and beliefs toward health warnings

\begin{tabular}{|c|c|c|}
\hline Variable & $\mathbf{O R} \dagger$ & 95\% C.I. \\
\hline Sex (Male) & 2.23 & $1.69-2.95^{*}$ \\
\hline \multicolumn{3}{|c|}{ Current knowledge of health warnings on Mo'assal packs } \\
\hline Front of Mo'assal pack & $1^{\wedge}$ & \\
\hline Side of Mo'assal pack & 1.35 & $0.79-2.30$ \\
\hline Back of Mo'assal pack & 1.39 & $0.80-2.41$ \\
\hline There are no warning messages & 0.60 & $0.44-0.81 *$ \\
\hline \multicolumn{3}{|c|}{ What do you think the effect of buying a Mo'assal packet would be on the individual } \\
\hline \multicolumn{3}{|c|}{ Make you think of the health risk of waterpipe smoking } \\
\hline less Likely & $1^{\wedge}$ & \\
\hline Makes no difference & 0.88 & $0.62-1.24$ \\
\hline More likely & 0.49 & $0.34-0.71 *$ \\
\hline \multicolumn{3}{|c|}{ How important is it that Jordan has health warnings on packs of Mo'assal } \\
\hline Important & $1^{\wedge}$ & \\
\hline No difference & 1.35 & $0.91-2.00$ \\
\hline Not important & 0.93 & $0.49-1.74$ \\
\hline Very important & 0.52 & $0.36-0.75^{*}$ \\
\hline Very unimportant & 1.41 & $0.76-2.62$ \\
\hline \multicolumn{3}{|c|}{$\begin{array}{l}\text { Do you think printing pictorial health warnings about harmful effects on Cigarettes and or waterpipe packs and device } \\
\text { will be/is an effective way to reduce its smoking among young people? }\end{array}$} \\
\hline Helps to prevent smoking & $1^{\wedge}$ & \\
\hline Helps to smoke & 0.82 & $0.52-1.29$ \\
\hline Helps to stop & 1.92 & $0.73-5.03$ \\
\hline No effect & 1.24 & $0.77-1.99$ \\
\hline
\end{tabular}

†OR means Odds Ratio, CI means Confidence Interval, $* \mathrm{p}<.05, \wedge$ Reference category.

\section{Discussion}

Our study reinforces the importance of adding health warning labels on waterpipe tobacco packages to help in the efforts of increasing the public knowledge and knowledge of the harmful effects of smoking. Our results also indicated that participants believe that including health warnings on Mo'assal packets in Jordan would help individuals to think about the harmful effects of waterpipe smoking. Additionally, participants believed that including health warning labels will be effective in assisting smokers to think about quitting.

Our results showed that tobacco smoking is more prevalent among males. Moreover, Males were times more likely to be smokers compared to females. These results are consistent previously reported studies among Jordanians and other parts of the world (Akl et al., 2011; Alzyoud et al., 2013; Bader et al., 2017; Khabour et al., 2012). 
Researchers demonstrated that this difference could be related to a combination of physiological, cultural, and behavioral factors (al'Absi, Nakajima, Allen, Lemieux, \& Hatsukami, 2015; Cosgrove et al., 2014; Sieminska \& Jassem, 2014). From neuroimaging studies Cosgrov and colleagues (Cosgrove et al., 2014) suggested that smoking activates male's reward pathways more than female's. This relate to the idea that males smoke for the reinforcing effects of nicotine, whereas females smoke to regulate mood or in response to tobacco-related cues. This indicate that the problem of smoking and particularly as our results indicate waterpipe smoking is a persisting health problem in need of serious efforts in prevention and smoking cessation.

Our findings indicate support for the inclusion of health warnings on Mo'assal package with a belief it would be effective for smokers to think about quitting. These findings are congruent with the existing evidence from both cigarette and waterpipe warning effectiveness studies (Borland et al., 2009; Francis et al., 2017; Francis, Mason, Ross, \& Noar, 2019; Girisken et al., 2017; Mostafa et al., 2018; Ratneswaran et al., 2014). Emery and colleagues (Emery, Romer, Sheerin, Jamieson, \& Peters, 2014) argued that when the person is exposed to health warnings on tobacco package it elicits high rates of cognitive processing such as perceived risk, they found that lower risk perceptions were associated with a desire to smoke, and feelings toward quitting especially among non-smokers. According to Emery and colleagues (Emery et al., 2014) cognitive reactions to health warnings are key mediators of the person subsequent behavioral responses.

In a recent systematic review of experimental studies (Francis et al., 2019) reported that health warnings on smokeless tobacco led to strong cognitive and affective reactions, negative pack attitudes and smoking attitudes, and increased intentions not to use tobacco products. Furthermore, Ratneswaran and colleagues (Ratneswaran et al., 2014) reported that they were more motivated to quit smoking when they were exposed to health warnings of the harmfulness of smoking to health particularly diseases such as heart disease, stroke, blindness, mouth and throat cancer, and lung cancer. Another factor of health warnings impacted people to think about quitting or not to smoke is negative affective reactions such as fear (Francis et al., 2017; Ratneswaran et al., 2014). Similarly, participants in our study believed that adding health warning will likely affect a person's thinking about the health risks of waterpipe smoking, will encourage none smokers not to initiate smoking, and arouse fear of waterpipe smoking. Among their tobacco control efforts policymakers should consider endorsing regulations to require tobacco companies to include health warnings on waterpipe tobacco packages similar to cigarettes.

Similar to any other project, the current study has limitations. The use of self-report measures could be considered as one of the current study limitations as this type of measurement relies on the recall and memory of the participants and grounded in subjectivity. Another limitation is the use of simple random and convenience samples, which limit representation of the population and generalizability of our results to the rest of the country.

\section{Conclusions}

In conclusion the current study shows that smokers were more likely to be aware of no health warnings on waterpipe tobacco packets. Additionally, participants believed that including health warnings on waterpipe tobacco package will help people to think about the harmful effects of waterpipe smoking. Another significant finding is that this study provides a picture that waterpipe smoking is a persisting serious problem among Jordanians. In agreement with previous studies, males were more likely to be waterpipe smokers, which indicate the need for an increase effort of education campaigns about harmful effects of waterpipe smoking. Since the current study only assess knowledge and beliefs of including health warnings on waterpipe packages future studies can be conducted with exposing participants to graphical health warning labels. We also recommend that future studies focus on the reactions and perceived effectiveness of exposure to warnings which could provide evidence for the impact of health warnings.

\section{Acknowledgments}

We would also like to thank Ministry of Education, Ministry of Health, Tobacco Free Jordan Society, International Federation of Medical Students Associations - Jordan for their collaboration with the project team.

\section{Funding}

The study was funded by the World Health Organization - Country Office of Jordan.

\section{Competing Interests Statement}

The authors declare that they have no conflict of interest. The authors alone are responsible for the views expressed in this article and they do not necessarily represent the views, decisions, or policies the WHO. The study was approved by Institutional Review Board (IRB) committee of Hashemite University. 


\section{References}

Abbadi, A., Alnahar, J., Zoghoul, S., Bsoul, A., Alarood, S., Al-Mistarehi, A.-H., \& Alzyoud, S. (2020). Waterpipe Nicotine Dependence and Depressive Symptoms among Adolescent Waterpipe and Dual Users. Journal of Environmental and Public Health, 2020, 2364571. https://doi.org/10.1155/2020/2364571

Aboaziza, E., \& Eissenberg, T. (2015). Waterpipe tobacco smoking: what is the evidence that it supports nicotine/tobacco dependence? Tobacco Control, 24(Suppl 1), i44. https://doi.org/10.1136/tobaccocontrol-2014-051910

Abu-Rmeileh, N. M. E., Alkhuffash, O., Kheirallah, K., Mostafa, A., Darawad, M., Al-Farsi, Y., .. Salloum, R. G. (2018). Harm perceptions of waterpipe tobacco smoking among university students in five Eastern Mediterranean Region countries: A cross-sectional study. Tobacco Induced Diseases, 16(May). https://doi.org/10.18332/tid/89966

Akl, E. A., Gunukula, S. K., Aleem, S., Obeid, R., Jaoude, P. A., Honeine, R., \& Irani, J. (2011). The prevalence of waterpipe tobacco smoking among the general and specific populations: a systematic review. BMC Public Health, 11(1), 244. https://doi.org/10.1186/1471-2458-11-244

al'Absi, M., Nakajima, M., Allen, S., Lemieux, A., \& Hatsukami, D. (2015). Sex differences in hormonal responses to stress and smoking relapse: a prospective examination. Nicotine \& tobacco research: official journal of the Society for Research on Nicotine and Tobacco, 17(4), 382-389. https://doi.org/10.1093/ntr/ntu340

Aljarrah, K., Ababneh, Z. Q., \& Al-Delaimy, W. K. (2009). Perceptions of hookah smoking harmfulness: predictors and characteristics among current hookah users. Tobacco Induced Diseases, 5(1), 16-16. https://doi.org/10.1186/1617-9625-5-16

Alzyoud, S., \& Massoud, F. (2020). Waterpipe and cigarette tobacco smoking and depressive symptoms among public school students in central Jordan. https://doi.org/10.1108/JHR-09-2019-0209

Alzyoud, S., Weglicki, L., Kheirallah, K., Haddad, L., \& Alhawamdeh, K. (2013). Waterpipe smoking among middle and high school Jordanian students: patterns and predictors. International journal of environmental research and public health, 10(12), 7068-7082. https://doi.org/10.3390/ijerph10127068

Bader, R. K., Shihab, R. A., Al-Rimawi, D. H., \& Hawari, F. I. (2017). Informing tobacco control policy in Jordan: assessing the effectiveness of pictorial warning labels on cigarette packs. BMC Public Health, 18(1), 84-84. https://doi.org/10.1186/s12889-017-4642-8

Bahelah, R., DiFranza, J. R., Ward, K. D., Eissenberg, T., Fouad, F. M., Taleb, Z. B., . . Maziak, W. (2017). Waterpipe smoking patterns and symptoms of nicotine dependence: The Waterpipe Dependence in Lebanese Youth Study. Addictive Behaviors, 74, 127-133. https://doi.org/10.1016/j.addbeh.2017.06.003

Borland, R., Yong, H.-H., Wilson, N., Fong, G. T., Hammond, D., Cummings, K. M., . . McNeill, A. (2009). How reactions to cigarette packet health warnings influence quitting: findings from the ITC Four-Country survey. Addiction (Abingdon, England), 104(4), 669-675. https://doi.org/10.1111/j.1360-0443.2009.02508.x

Center for Disease Control and Prevention, C. (2017). Global Tobacco Surveillance System Data (GTSSData) 2017. Retrieved from https://www.cdc.gov/tobacco/global/gtss/gtssdata/index.html

Chaouachi, K. (2006). A critique of the WHO TobReg's "Advisory Note" report entitled: "Waterpipe tobacco smoking: health effects, research needs and recommended actions by regulators". Journal of Negative Results in BioMedicine, 5(1), 17. https://doi.org/10.1186/1477-5751-5-17

Cobb, C., Ward, K. D., Maziak, W., Shihadeh, A. L., \& Eissenberg, T. (2010). Waterpipe tobacco smoking: an emerging health crisis in the United States. American journal of health behavior, 34(3), 275-285. https://doi.org/10.5993/AJHB.34.3.3

Cobb, C. O., Khader, Y., Nasim, A., \& Eissenberg, T. (2012). A multiyear survey of waterpipe and cigarette smoking on a US university campus. Journal of American college health: $J$ of ACH, 60(7), 521-527. https://doi.org/10.1080/07448481.2012.692416

Cosgrove, K. P., Wang, S., Kim, S.-J., McGovern, E., Nabulsi, N., Gao, H., . . . Morris, E. D. (2014). Sex Differences in the Brain\&\#039;s Dopamine Signature of Cigarette Smoking. The Journal of Neuroscience, 34(50), 16851. https://doi.org/10.1523/JNEUROSCI.3661-14.2014

Department of Statistics, D.-J. (2019). Population and Housing Censuse. Retrieved from 
http://dosweb.dos.gov.jo/censuses/population_housing/

Emery, L. F., Romer, D., Sheerin, K. M., Jamieson, K. H., \& Peters, E. (2014). Affective and cognitive mediators of the impact of cigarette warning labels. Nicotine \& tobacco research: official journal of the Society for Research on Nicotine and Tobacco, 16(3), 263-269. https://doi.org/10.1093/ntr/ntt124

Francis, D. B., Hall, M. G., Noar, S. M., Ribisl, K. M., \& Brewer, N. T. (2017). Systematic Review of Measures Used in Pictorial Cigarette Pack Warning Experiments. Nicotine \& tobacco research: official journal of the Society for Research on Nicotine and Tobacco, 19(10), 1127-1137. https://doi.org/10.1093/ntr/ntx082

Francis, D. B., Mason, N., Ross, J. C., \& Noar, S. M. (2019). Impact of tobacco-pack pictorial warnings on youth and young adults: A systematic review of experimental studies. Tobacco Induced Diseases, 17(May). https://doi.org/10.18332/tid/108614

Girisken, Y., Eser Telci, E., Arikan, E., \& Kefallonitis, E. (2017). The Perception of Warning Signs at Different Cultures. In Strategic Innovative Marketing (pp. 253-258). https://doi.org/10.1007/978-3-319-33865-1_32

Haddad, L., Kelly, D. L., Weglicki, L. S., Barnett, T. E., Ferrell, A. V., \& Ghadban, R. (2016). A Systematic Review of Effects of Waterpipe Smoking on Cardiovascular and Respiratory Health Outcomes. Tobacco Use Insights, 9, 13-28. https://doi.org/10.4137/TUI.S39873

Hawari, F. I., Bader, R. K., Beano, H. M., Obeidat, N. A., Ayub, H. S., Habashneh, M. A., . . Novotny, T. E. (2011). Perceptions of young Jordanian adults to proposed anti-tobacco pictorial warning labels. BMC Public Health, 11(1), 414. https://doi.org/10.1186/1471-2458-11-414

Jawad, M., Charide, R., Waziry, R., Darzi, A., Ballout, R. A., \& Akl, E. A. (2018). The prevalence and trends of waterpipe tobacco smoking: A systematic review. PLOS ONE, 13(2), e0192191. https://doi.org/10.1371/journal.pone.0192191

Jordan Standards and Metrology Organization. (2014). Tobacco and tobacco products -Tobacco molasses JS 787:2014 (Vol. 787, 2014). Jordan Standarda and Metrology Organization.

Khabour, O. F., Alzoubi, K. H., Eissenberg, T., Mehrotra, P., Azab, M., Carroll, M. V., . . Primack, B. A. (2012). Waterpipe tobacco and cigarette smoking among university students in Jordan. The international journal of tuberculosis and lung disease : the official journal of the International Union against Tuberculosis and Lung Disease, 16(7), 986-992. https://doi.org/10.5588/ijtld.11.0764

Maziak, W. (2011). The global epidemic of waterpipe smoking. Addictive Behaviors, 36(1-2), 1-5. https://doi.org/10.1016/j.addbeh.2010.08.030

Maziak, W., Fouad, F. M., Asfar, T., Hammal, F., Bachir, E. M., Rastam, S., . . Ward, K. D. (2004). Prevalence and characteristics of narghile smoking among university students in Syria. Int J Tuberc Lung Dis, 8(7), 882-889.

Maziak, W., Taleb, Z. B., Bahelah, R., Islam, F., Jaber, R., Auf, R., \& Salloum, R. G. (2015). The global epidemiology of waterpipe smoking. Tobacco Control, 24(Suppl 1), i3. https://doi.org/10.1136/tobaccocontrol-2014-051903

Mostafa, A., Mohammed, H. T., Hussein, R. S., Hussein, W. M., Elhabiby, M., Safwat, W., . . Aboul Fotouh, A. (2018). Do pictorial health warnings on waterpipe tobacco packs matter? Recall effectiveness among Egyptian waterpipe smokers \& non-smokers. PLOS ONE, 13(12), e0208590. https://doi.org/10.1371/journal.pone.0208590

Ratneswaran, C., Chisnall, B., Drakatos, P., Sivakumar, S., Sivakumar, B., Barrecheguren, M., . . S Steier, J. (2014). A cross-sectional survey investigating the desensitisation of graphic health warning labels and their impact on smokers, non-smokers and patients with COPD in a London cohort. BMJ Open, 4(7), e004782. https://doi.org/10.1136/bmjopen-2013-004782

Shihadeh, A., \& Saleh, R. (2005). Polycyclic aromatic hydrocarbons, carbon monoxide, "tar", and nicotine in the mainstream smoke aerosol of the narghile water pipe. Food and Chemical Toxicology, 43(5), 655-661. https://doi.org/10.1016/j.fct.2004.12.013

Shihadeh, A., Schubert, J., Klaiany, J., El Sabban, M., Luch, A., \& Saliba, N. A. (2015). Toxicant content, physical properties and biological activity of waterpipe tobacco smoke and its tobacco-free alternatives. Tobacco Control, 24(Suppl 1), i22. https://doi.org/10.1136/tobaccocontrol-2014-051907

Sieminska, A., \& Jassem, E. (2014). The many faces of tobacco use among women. Medical science monitor: international medical journal of experimental and clinical research, 20, 153-162. 
https://doi.org/10.12659/MSM.889796

Smith-Simone, S., Maziak, W., Ward, K. D., \& Eissenberg, T. (2008). Waterpipe tobacco smoking: knowledge, attitudes, beliefs, and behavior in two U.S. samples. Nicotine \& tobacco research: official journal of the Society for Research on Nicotine and Tobacco, 10(2), 393-398. https://doi.org/10.1080/14622200701825023

Sterling, K. L., \& Mermelstein, R. (2011). Examining hookah smoking among a cohort of adolescent ever smokers. Nicotine \& tobacco research: official journal of the Society for Research on Nicotine and Tobacco, 13(12), 1202-1209. https://doi.org/10.1093/ntr/ntr146

Tamim, H., Al-Sahab, B., Akkary, G., Ghanem, M., Tamim, N., El Roueiheb, Z., . . Afifi, R. (2007). Cigarette and nargileh smoking practices among school students in Beirut, Lebanon. American journal of health behavior, 31(1), 56-63. https://doi.org/10.5993/AJHB.31.1.6

Tucktuck, M., Ghandour, R., \& Abu-Rmeileh, N. M. E. (2017). Waterpipe and cigarette tobacco smoking among Palestinian university students: a cross-sectional study. BMC Public Health, 18(1), 1. https://doi.org/10.1186/s12889-017-4524-0

Waziry, R., Jawad, M., Ballout, R. A., Al Akel, M., \& Akl, E. A. (2016). The effects of waterpipe tobacco smoking on health outcomes: an updated systematic review and meta-analysis. International Journal of Epidemiology, 46(1), 32-43. https://doi.org/10.1093/ije/dyw021

World Health Organization Advisory note, W. (2015). Advisory note: waterpipe tobacco smoking: health effects, research needs and recommended actions for regulators (2nd ed., 978924150846 9).

World Health Organization, W. (2003). WHO Framework Convention on Tobacco Control FCTC. In.

World Health Organization, W. (2018). WHO global report on trends in prevalence of tobacco smoking 2000-2025 (2nd ed.).

\section{Copyrights}

Copyright for this article is retained by the author(s), with first publication rights granted to the journal.

This is an open-access article distributed under the terms and conditions of the Creative Commons Attribution license (http://creativecommons.org/licenses/by/4.0/). 